\title{
On the Cultivation of Undergraduates' Ability of Innovation and Entrepreneurship in Economic Management Based on Employment Ability Perspective
}

\author{
Runxiang $\mathrm{Xu}^{1, \mathrm{a}}$ and Mingzhu $\mathrm{Li}^{2, \mathrm{~b}}$ \\ ${ }^{1}$ College of Economics and Management, Weifang University, Weifang 261061, China \\ ${ }^{2}$ College of Foreign Languages, Inner Mongolia Agricultural University, Huhhot, 010018, China \\ acyxrx@126.com, ${ }^{\mathrm{b}} 19116474 @ q q . c o m$
}

Keywords: Economic management; College students; Innovation; Entrepreneurship

\begin{abstract}
At present, with the expansion of enrollment in colleges and universities, the employment situation of university graduates has become increasingly severe, and economic management majors once hailed as "popular". Due to unreasonable duplication of settings, these professional graduates have obviously oversupply. At the same time, due to the special nature of graduates of economic management, the practical requirements of graduates are high, which makes the employment of economic management graduates face many difficulties. From the perspective of employability, the article analyzes the status quo of innovation and entrepreneurship education for economic management students from the aspects of curriculum system and practical teaching. It finds that the ability of innovation and entrepreneurship of graduates of this type lags behind the practical needs of economic and social development. It is difficult to adapt its employability to meet the requirements of the labor and employment market in the short term. Then analyze the main problems existing, and put forward some feasible suggestions for training the ability of innovation and entrepreneurship of economic management from the perspective of innovation of ability training mechanism, so as to achieve the purpose of improving employability.
\end{abstract}

\section{Introduction}

Since the beginning of the 21 st century, with the sustained economic and social development, the demand for various types of talents has continued to increase, and the requirements for talented people's employability have become increasingly diversified. There is an urgent need for innovative and entrepreneurial talents, which puts forward new requirements for the cultivation of college students' abilities in innovation and entrepreneurship. Moreover, strengthening innovation and entrepreneurship education is also a realistic requirement for the development of higher education itself, and it is also an inevitable choice to solve the employment difficulties of college students. Although colleges and universities are exploring and practicing innovation and entrepreneurship education, universities and governments have also issued a series of preferential policies and measures to encourage and support college students to start their own businesses. The entrepreneurial ability of economic management students is mainly composed of professional skills, management skills, coordinating and communication skills, and innovation ability. This paper starts from the actual situation of employment, and considers the actualities of economic management, students' characteristics and needs, and the characteristics of economic and social dynamic changes. From a theoretical point of view, we will build a talent management system for managing undergraduates that is capable of coordinating entrepreneurial skills from a macro-level national government, a meso-level social school, and a micro-level teacher-student family. From the perspective of practice, we will build a carrier for academic competition innovation and flexibility. The use of experimental training, etc., fully meets the requirements of the characteristics of the cultivation of entrepreneurial talents in economic management colleges and universities.

The Significance of Cultivating Students' Creative and Entrepreneurial Ability in Economic Management. Cultivating students' ability for innovation and entrepreneurship is the need for financial institutions to implement the national strategy of promoting the development 
of innovative countries.

China will build an innovative country by 2020, making the development of science and technology a powerful support for economic and social development. The core of this major strategy is to continuously enhance the ability of independent innovation of talents. The ability of independent innovation cannot develop without the cultivation of entrepreneurial ability. The discipline structure and specialty layout of economic and management majors in financial and economic institutions and their knowledge and knowledge structure are more conducive to the enhancement of entrepreneurial awareness and the cultivation of entrepreneurial abilities. This will greatly promote the development of innovative talents, the development of an innovative culture, the creation of a social entrepreneurial atmosphere, and the improvement of independent innovation capabilities, which will be conducive to the implementation of an innovative national strategy.

Cultivating the entrepreneurial ability of college students is a requirement for cultivating a spirit of innovation and transforming the concept of employment.

The spirit of innovation is an important embodiment of the humanistic quality of college students. Entrepreneurship education is implemented to focus on entrepreneurial content experience. Through this experience, students can acquire perceptual knowledge. This is a prerequisite for successful entrepreneurship education. Therefore, entrepreneurship education can consciously guide students in the effective implementation of relevant content experiences, with a purposeful and organized search for change, and identify opportunities from various changes. This is a process of innovation and exploration that is full of risks and hardships. It plays an irreplaceable role in fostering the innovative spirit of university students in economic management. At the same time, students' entrepreneurial abilities are encouraged, active entrepreneurship is encouraged, passive employment concepts are transformed into active entrepreneurial concepts, students are chosen as their career choices, and their professional skills and interests are organically combined to achieve their own goals in life and the value of life, to a certain extent, can ease the current employment pressure.

Improve the quality of personnel training for economic management students and promote the need for discipline development.

To cultivate students' entrepreneurial ability, students need to build a sound and reasonable knowledge structure and have a wide range of knowledge backgrounds, including multidisciplinary knowledge such as economics, management, sociology, and law. Therefore, in the process of fostering entrepreneurial ability, financial and economic institutions can continue to cross, infiltrate, graft, and integrate the aforementioned disciplines with the original disciplines on the basis of the strength of the original economic management disciplines, and to break through the previously fragmented and single barriers to knowledge, promote the continuous development and improvement of disciplines. At the same time, students are encouraged to use a variety of knowledge in the process of constructing their own knowledge structure, optimize and integrate various types of knowledge, and transform the spark of innovative thinking in their minds into real-world entrepreneurial practices. As a result, the innovative qualities of students will be nurtured and developed, hands-on skills and entrepreneurial skills will be tempered and improved, and the quality of personnel training will also be improved.

Status Quo of Cultivation of Innovative and Entrepreneurial Ability of Economic Management Undergraduate. For undergraduates majoring in economics and management majors, due to their professional characteristics, the direction of student employment refers directly to the important management units of business units and will involve important trade secrets such as finance, contracts, and programs. Therefore, employers put forward high requirements for graduates' abilities, and graduates reflect many problems in the employment process, which are reflected in: The theoretical knowledge is not solid and the practical ability is insufficient; Good high heron, lack of sense of integrity; The lack of basic professional qualities of hard-working, hard-working struggle; Communication skills, lack of interpersonal skills, etc.

The emergence of these problems can be summarized as follows: students' self-knowledge confusion, lack of clear career goals during college; lack of a clear understanding of the actual workplace, including social needs, the company's quality of the entire staff morality in terms of 
demand, practical experience, the lack of actual work intensity; Insufficient practice to integrate into social practice as soon as possible; etc. The existence of these problems is obviously related to the various shortcomings we have in carrying out vocational guidance education for students.

There are several deficiencies in the practical teaching of vocational guidance in economic management majors in colleges and universities.

The definition and contents of the career guidance are confused.

At present, many people are not clear enough about the definition and content of career guidance. They simply think that career guidance is employment guidance. When students are close to graduation, they will teach about employment skills, employment policies, and provide relevant employment information. These temporary cramming practices obviously fail to meet the training needs of economic management talents.

The vocational guidance practice has a single content and method.

In the past, we simply carried out vocational guidance through some course teaching and lectures. We could not allow students to truly experience the workplace. The understanding of the actual work situation can only be from theory to theory, and it is out of touch with reality.

The career guidance system is outside the school's professional teaching practice system.

The traditional teaching practice system is more concerned with how students apply professional theoretical knowledge to practice to improve practical ability. Less consideration is given to the cultivation of professional awareness and professional abilities in practice, resulting in professional teaching practice and vocational guidance. In practice, each segmented environment does not reflect the principle of full-time and full-time career guidance.

Perfecting the Ability-training Mechanism and Improving the Innovative and Entrepreneurial Ability of Economic Management Students. At present, the cultivation of economic and management undergraduates' innovative and entrepreneurial abilities is still at the exploratory stage of exploration and development. The current grim employment situation highlights the growing importance of innovation and entrepreneurship training. Therefore, the main tasks for the economic management students to cultivate their innovative and entrepreneurial abilities are to improve the training mode, change the ideology, build a faculty, reform the curriculum system, create a creative and entrepreneurial atmosphere, and enhance the employability and employment adaptability of economic management students.

Here, combined with the major problems existing in the cultivation of innovation and entrepreneurship of economics and management college students and the demand trends of innovative management and entrepreneurial ability of undergraduate students, we will actively improve the ability-building mechanism and enhance the ability to innovate and innovate, so as to achieve the fundamental purpose of improving the employability of economic management students.

Take the employment ability as the leading factor and change the mode of cultivating innovation and entrepreneurship.

Employment is the inevitable career goal for most college students. Therefore, cultivating employability has become the primary goal of economic education for university students in academic education. This requires the employment ability as the leading factor to strengthen the cultivation of innovation and entrepreneurship. Specifically speaking, according to the current training mode of various majors of economic management, the investment intensity of investment in innovation and entrepreneurship education for undergraduates of economic management is increased, and the basic requirements for the cultivation of innovation and entrepreneurship are scientifically and rationally implanted into the existing teaching system to clarify students. The main position in the innovation and entrepreneurship education system guides students in innovation and entrepreneurship learning and improves their ability to innovate and innovate. In accordance with the requirements of cultivating innovative and entrepreneurial talents, build a platform for innovation and entrepreneurial talents training, inspire students' innovative thinking, encourage and support student self-startup pilot projects, prioritize support for promising student innovation and entrepreneurship projects, and actively coordinate all parties to incubate students' 
venture projects with market prospects.

Cultivate the awareness of innovation and entrepreneurship, change the concept of employment and career choice of economic management students.

Consciousness and concept are the precursors of college students' employment and entrepreneurial behavior. Through professional knowledge education, students in economic management are encouraged to innovate and entrepreneurial ideology. Students can actively learn innovative entrepreneurial knowledge, fully explore students' creative potential, encourage students to make bold ventures, use entrepreneurship to promote employment, broaden employment channels, and improve the employment of economic management students. Ability to encourage students with a certain talent to create new technologies or new products combined with what they have learned, make full use of the school's quality education and teaching resources and government preferential business support policies, identify entrepreneurial opportunities, capture entrepreneurial projects, and provide personal and family social resources Start-up capital or other ways to prepare for venture capital to carry out innovation and entrepreneurship practices to achieve the entrepreneurial dream of college students.

Improve the teacher training system and build a professional teacher team with diverse skills.

The quality of innovation and entrepreneurship training depends critically on the professional and professional teaching staff. Implement a plan that combines "going out" with "inviting in". Distribute professional teachers of economic management to Tsinghua University and other universities at home and abroad to carry out innovation and entrepreneurship education to conduct further studies or visits, encourage and subsidize professional teachers of economic management to actively participate in innovation and entrepreneurship academic conferences and advanced seminars to learn experience exchange experiences; The mode of enterprise cooperation encourages professional teachers of economic management to work part-time or hang jobs with various types of enterprises, deepen cooperation and exchanges among enterprises, and incorporates teachers' performance assessment content, thereby strengthening teachers' professional awareness of workplace orientation and corporate operations. Inviting famous teachers who are engaged in innovation and entrepreneurship education or entrepreneurs or alumni who have succeeded in entrepreneurship are guest professors or lecture professors. Regular lectures are given to economic management teachers and students to teach entrepreneurial experiences, teach entrepreneurial skills, broaden their horizons, and enhance students' Interest and enthusiasm of innovation and entrepreneurship; Intensify the introduction of high-level talents for innovation and entrepreneurship education, and orderly promote the diversification of teachers' teaching skills and the professionalization of practice education.

Adapt to the needs of the job market and optimize the knowledge structure and curriculum system of the subject.

Pay attention to the integration of disciplines and complementary knowledge, closely link the needs of the job market, and form a scientific and rational curriculum system. In accordance with the requirements of modern economic and social development on the multiple requirements of economic management students' employability, the curriculum system of economic management disciplines will be set from the perspective of cultivating students' ability for innovation and entrepreneurship. Basic courses will be set up according to the characteristics of the subject, professional courses will be set up in accordance with employment requirements, elective courses will be set up in connection with individual characteristics. It encourages students to minor in other subjects in the subject area, and train compound management talents.

\section{Summary}

With the popularization of higher education, graduates entering the society will face more severe tests. This is especially true for graduates of economic management majors. Faced with this situation, economic and management students should broaden their horizons of knowledge, improve their overall quality, and constantly cultivate their ability to innovate and innovate, thereby enhancing their employability. Keeping pace with the requirements of economic and social 
development and the changing characteristics of the labor market, the cultivation of innovation and entrepreneurship for economic management students should focus on activating students' innovative and entrepreneurial thinking, enhancing employability, improving the quality of employment, encouraging more students to participate in entrepreneurship, and achieving happiness in employment and entrepreneurship.

\section{References}

[1] Eesley C E, Miller W F: Impact: Stanford University's Economic Impact via Innovation and Entrepreneurship [J]. Social Science Electronic Publishing, 2013.

[2] Dzidrov M, Cvetkov S, Stojanova T, et al: Influence of Innovation and Entrepreneurship on the Economic Growth[J]. 2014.

[3] Min G E, Chen X P: Practice and Exploration on the Training of Economic Management Talents with "Innovation and Entrepreneurship" in Local Colleges and Universities[J]. Value Engineering, 2012.

[4] Moser P. Patents and Innovation: Evidence from Economic History[J]. Social Science Electronic Publishing, 2013, 27(1):23-44.

[5] Lynn Mytelka: Innovation and Economic Development[J]. Books, 2015, 15(2):3-35.

[6] Moser P. Patents and Innovation: Evidence from Economic History[J]. Social Science Electronic Publishing, 2013, 27(1):23-44.

[7] Donald F. Ferguson, Christos Nikolaou, Jakka Sairamesh, et al: Economic Models for Allocating Resources in Computer Systems[J]. Market Based Control of Distributed Systems World Scientific, 2015:156--183.

[8] Brogaard J, Detzel A L: The Asset Pricing Implications of Government Economic Policy Uncertainty[J]. Social Science Electronic Publishing, 2016, 61(1):3-18.

[9] Mclean W, Gillis J, Waller R: The BC Community Pharmacy Asthma Study: A study of clinical, economic and holistic outcomes influenced by an asthma care protocol provided by specially trained community pharmacists in British Columbia[J]. Canadian Respiratory Journal Journal of the Canadian Thoracic Society, 2016, 10(4):195.

[10]Li S, Gong L, Pan S: Structural Change and Economic Growth[J]. Social Science Electronic Publishing, 2017.

[11] Neil A L, Carr V J, Chong H Y, et al: Global economic burden of schizophrenia: response to authors' reply[J]. Neuropsychiatric Disease \& Treatment, 2017, 13:457-458.

[12] Klein P A: Unemployment and Technical Innovation; A Study of Long Waves and Economic Development, by Christopher Freeman; John Clark; Luc Soete[J]. Journal of Economic Issues, 2016, 17(3):803-808.

[13] Voyant O, Bonnet M, Tabchoury P, et al: Contribution of the Socio-economic Management Control to Steering Balanced and Sustainable Company Overall Performance[J]. Society \& Business Review, 2017, 12(2). 